\title{
Fruit and vegetable consumption and self-reported functional health in men and women in the European Prospective Investigation into Cancer-Norfolk (EPIC-Norfolk): a population-based cross-sectional study
}

\author{
Phyo K Myint ${ }^{1,2, *}$, Ailsa A Welch ${ }^{1}$, Sheila A Bingham ${ }^{3}$, Paul G Surtees ${ }^{1}$, Nicholas \\ WJ Wainwright ${ }^{1}$, Robert N Luben ${ }^{1}$, Nicholas J Wareham ${ }^{4}$, Richard D Smith ${ }^{2}$, lan \\ M Harvey ${ }^{2}$, Nicholas E Day ${ }^{1}$ and Kay-Tee Khaw ${ }^{1}$ \\ ${ }^{1}$ Department of Public Health and Primary Care, University of Cambridge, UK: ${ }^{2}$ School of Medicine, Health Policy \\ and Practice, University of East Anglia, Norwich, UK: ${ }^{3}$ MRC Dunn Human Nutrition Unit, Cambridge, UK: \\ ${ }^{4}$ MRC Epidemiology Unit, Cambridge, UK
}

Submitted 31 January 2006: Accepted 10 August 2006

\begin{abstract}
Objectives: To investigate the association between fruit and vegetable consumption and self-reported physical and mental functional health measured by an anglicised short-form 36-item questionnaire (UK SF-36).

Design: Population-based cross-sectional study.

Setting: General community in Norfolk, UK.

Subjects: A total of 16792 men and women aged 40-79 years recruited from general practice population registers as part of the European Prospective Investigation into Cancer (EPIC)-Norfolk study, who completed food-frequency questionnaires in 1993-1997 and Health and Life Experiences Questionnaires 18 months later, were enrolled in the study.

Results: Mean SF-36 physical component summary scores increased significantly with increasing total fruit and vegetable consumption in both men and women $(P<$ 0.0001 for trend). Men and women in the top quartile of consumption compared with the bottom quartile had a significantly higher likelihood of reporting good physical health (defined as a score $\geq 55$ ); odds ratio (OR) 1.30, 95\% confidence interval (CI) 1.11-1.53 for men and OR 1.28, 95\% CI 1.11-1.48 for women, after controlling for age, body mass index, smoking, education, social class, prevalent illness and total energy intake. Exclusion of current smokers and people with prevalent illness did not alter the associations.

Conclusion: Higher fruit and vegetable consumption is associated with better selfreported physical functional health within a general population. Increasing daily intake by two portions of fruit and vegetables was associated with an $11 \%$ higher likelihood of good functional health. Since the current average consumption of fruit and vegetables in the UK is about three portions, the recommended 'five a day' strategy may have additional benefit for functional as well as other health outcomes in the population.
\end{abstract}

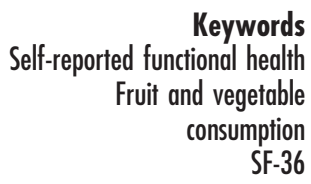

There is an increasing interest in role of diet in health. A high intake of fruit and vegetables is well recognised as contributing to good health ${ }^{1}$. It has been reported to be protective for many conditions, including cardiovascular disease $^{2-6}$ and cancer ${ }^{7-11}$, though not necessarily for others $^{12,13}$. We have previously reported that a high intake of plant foods, as indicated by plasma vitamin C levels, is inversely related to mortality in men and women ${ }^{14}$. There is an accumulating body of evidence supporting the inverse relationship between fruit and vegetable consumption and mortality in various settings ${ }^{15-17}$.
The relationship between high fruit and vegetable intake and objective health outcomes is well established. Yet, little is known about the relationship between fruit and vegetable consumption and an individual's selfreported physical and mental well-being. Functional health is an important concern in an ageing population.

In this study, a widely used health-related quality of life measure, the 36-item short-form questionnaire (the SF-36), was used to investigate the association between fruit and vegetable consumption and physical and mental functional health in men and women living in the general community. 


\section{Methods}

The study population comprises men and women recruited from general practices in Norfolk, UK. This includes the city of Norwich as well as surrounding small towns and rural areas. Men and women aged 4079 years were identified from collaborating general practice registers and were invited by mail to participate in the baseline survey conducted between 1993 and 1997 as part of the Norfolk component of the European Prospective Investigation into Cancer (EPIC-Norfolk) study. Out of a total of 77603 invited individuals, 30445 men and women ( $\sim 40 \%)$ consented to participate. Detailed descriptions of the recruitment and study methodology have been previously reported $^{18}$.

\section{Predictor variables}

Fruit and vegetable consumption was assessed by a foodfrequency questionnaire (FFQ) collected at the baseline clinic visit. The EPIC-FFQ comprised a list of 130 foods. For fruit, participants were asked to choose between nine responses ranging from never consumed or consumed less than once per month, to consumed more than six times per day based on the estimated average consumption of one item of fruit (e.g. an apple, a pear or half of a grapefruit) or a medium serving of fruit (e.g. grapes, strawberries, tinned or dried fruit) over the last year. For seasonal fruit, such as peaches and strawberries, participants were asked to estimate their average consumption when the fruit is in season. For vegetables, the same options were given for the consumption of a medium serving of fresh, frozen or tinned vegetables. Missing choices, or two or more choices per line, were omitted from the analysis. FFQs were also excluded from the analysis if the frequency of 10 or more food items was missing. An in-house computer program, CAFE (Compositional Analyses from Frequency Estimates), was developed for data entry and analysis ${ }^{19}$. The resulting data concerning the average daily consumption of fruit and vegetables in grams per day was combined to obtain the total daily average intake of fruit and vegetables.

\section{Outcome variables}

Eighteen months after this baseline survey, the surviving participants then aged $41-80$ years were asked to complete the Health and Life Experiences Questionnaire (HLEQ), which included the anglicised version of the short-form 36 $(\mathrm{UK} \mathrm{SF}-36)^{20}$, by mail. Of the total eligible EPIC-Norfolk sample, 20921 participants (73.2\%) responded ${ }^{21}$.

The SF-36 contains 36 items which measure an individual's perceived well-being in terms of frequency and intensity of feeling states. It measures self-reported health across eight dimensions: physical functioning; social functioning; role limitation due to physical problems; role limitation due to emotional problems; mental health; energy/vitality; pain; and general health perception. For each dimension, an overall score is obtained from the scores from individual relevant responses of questions concerned with that particular dimension. For each dimension, these raw scores are then transformed into a scale from 0 to 100 , using a scoring system provided, where 0 represents poor health and 100 represents good health for each dimension $^{21}$. The overall result is then a 'health profile' across each of the eight dimensions.

The Physical Component Summary (PCS) and Mental Component Summary (MCS) scores were derived according to algorithms specified by the original developers ${ }^{22,23}$. They were created by aggregating across the eight SF-36 subscales after transforming to $Z$-scores and multiplying by their respective factor score coefficients and standardised as T-scores with mean of 50 and standard deviation (SD) of $10^{21}$.

\section{Measurements}

Anthropometric measures including height and weight were determined for all subjects who attended clinic assessment at baseline using a standardised protocol ${ }^{24}$. Body mass index (BMI) was calculated as weight in kilograms divided by the square of the height in metres: weight $(\mathrm{kg}) /(\text { height }(\mathrm{m}))^{2}$. Social class at baseline was classified according to the Registrar General's occupationbased classification scheme in which people with similar levels of occupational skill are allocated into one of five groups $^{25}$. Social class I consists of professionals, social class II includes managerial and technical occupations, social class III is subdivided into non-manual skilled workers and manual skilled workers, social class IV consists of partly skilled workers, and social class $\mathrm{V}$ comprises unskilled manual workers.

Educational status was based on the highest qualification attained and was categorised into four groups: degree or equivalent; A-level or equivalent; O-level or equivalent; and less than O-level/no qualifications. O-Level or equivalent indicates educational attainment to the usual minimal school leaving age of 15 and A-level to the educational attainment to age of 17 years.

Social class was reclassified into 'non-manual' (social classes I, II and III non-manual) and 'manual' (social classes III manual, IV and V) and educational attainment into 'at least O-level' (O-level, A-level and degree) and 'no qualifications' (lower than O-level or no qualification).

Cigarette smoking status was derived from responses to the questions 'Have you ever smoked as much as one cigarette a day for as long as a year?' and 'Do you smoke cigarettes now?' From these questions, smoking status was classified as current smoker, former smoker or those who had never smoked. On a baseline health questionnaire, the participants were asked, 'Has the doctor ever told you that you have any of the following?', followed by a list of various conditions. For this study, prevalent illness was defined as the presence of self-reported major chronic 
illnesses, which includes cancer, stroke, myocardial infarction and diabetes mellitus.

From the FFQs, total energy intake was calculated by the CAFE program using formulae from food tables and applying portion weighting. Resulting estimates of the daily energy intake in kilocalories was used.

Participants who did not have data on fruit and vegetable consumption calculated from FFQs and SF-36 PCS and MCS scores were excluded from the study.

\section{Statistical analyses}

Statistical analyses were performed using SPSS Version 12.0.1 (SPSS Inc.). The analyses were undertaken separately for men and women. Age at the time of completion of the SF-36 was included as a covariate in all regression models. Those participants with missing values for covariates were excluded from individual regression analyses.

The unadjusted means of SF-36 PCS and MCS scores were tabulated according to the quartiles of total fruit and vegetable consumption in $\mathrm{g} \mathrm{day}^{-1}$. The analysis of variance and general linear model test for linearity was used. A $P$-value of $<0.05$ (two sided) was regarded as statistically significant.

The relationship between daily total fruit and vegetable intake by its quartile categories and functional health measured by PCS and MCS was analysed. First age-adjusted, and secondly age-, energy intake-, BMI-, smoking-, education-, social class- and prevalent illnessadjusted models were constructed to examine the confounding effect of age compared with other confounders. We chose these covariates since they not only showed significant association with fruit and vegetable consumption but also could influence functional health. We repeated the analyses with physical functioning and mental health subscale values, which contributed mainly to PCS and MCS, respectively, to examine the validity and repeatability of the associations ${ }^{26,27}$.

Multiple linear regression analyses were performed to assess the relationship between total fruit and vegetables intake as a continuous variable (increase in consumption of one portion $(80 \mathrm{~g})$ ) and functional health after adjusting for age, smoking, social class, education, prevalent illnesses and total daily energy intake. We repeated the analyses after excluding those who currently smoke and those who reported any major long-term illnesses.

A PCS and MCS score of $\geq 55$ ( 0.5 SD above population mean score) was used to identify people in good physical and mental functional health to examine the clinical effect size of observed differences in functional health scores. We estimated the likelihood of being in this arbitrarily defined good health status category by quartiles of total fruit and vegetable consumption for both men and women using multivariately adjusted logistic regression models. Similar models were constructed adjusting for the same covariates as in the multiple linear regressions.
We also estimated the likelihood of being in the good functional health status category with each increase in consumption of two portions of fruit and vegetables (160 g), controlling for age, sex and the above covariates. The purpose of this analysis was to investigate how differences in the mean values are translated into potential practical impact.

\section{Results}

Of 30445 who consented to participate, $\sim 25000$ individuals attended the first health check and also completed FFQs. Of 20921 participants who completed the SF-36, SF-36 component summary scores were imputable for 19535 individuals. Not all participants who completed FFQs responded to the SF-36 questionnaire, and vice versa. Therefore, there were a total of 16792 (7416 men and 9376 women) with complete data on total fruit and vegetable consumption, derived from FFQs at baseline, and the SF-36 completed 18 months later. Excluding current smokers left 14986 men and women, and after excluding those with self-reported prevalent illness at baseline there were 14976 men and women.

Table 1 shows the distribution of sample characteristics by gender-specific quartiles of total fruit and vegetable intake for the entire available sample. Category 1 represents the lowest quartile whilst category 4 represents the highest quartile of consumption. In men and women, higher total fruit and vegetable intake was positively associated with higher energy intake, higher BMI, increasing age and having a prevalent illness. It was negatively associated with smoking, manual occupational social class, and lower level of education. Higher PCS and MCS scores (i.e. better physical and mental functional health) were reported by people with higher fruit and vegetable consumption in this unadjusted model.

Table 2 shows the SF-36 PCS and MCS mean scores by quartile of total fruit and vegetable consumption controlling for age (model A), and age, energy intake, BMI, smoking, education, social class and prevalent illness (model B). In men and women, there was a significant association between higher level of total fruit and vegetable intake and physical functional health. A less consistent association between men and women was observed with regard to the relationship between higher total fruit and vegetable intake and mental functional health. There were no significant differences in results observed between model A and B for both PCS and MCS in both sexes. Repeating the analyses, using physical functioning and mental health subscales showed a significant increase in these subscale scores with higher total fruit and vegetable consumption quartile categories (not shown).

Table 3 shows multiple linear regression analyses examining the relationship between an increase in daily intake of $80 \mathrm{~g}$ (one portion) of fruit and vegetables and self-reported physical and mental functional health 
Table 1 Distribution of sample characteristics of 7416 men and 9376 women aged 40-79 years in EPIC-Norfolk by total fruit and vegetable consumption

\begin{tabular}{|c|c|c|c|c|c|}
\hline & \multicolumn{5}{|c|}{ Category of total fruit and vegetable consumption } \\
\hline & 1 & 2 & 3 & 4 & $P$ for trend \\
\hline $\operatorname{Men}(n)$ & 1854 & 1854 & 1854 & 1854 & \\
\hline Quartile ranges ( $\mathrm{g} \mathrm{day}^{-1}$ ) & up to 259 & 259 to $<369$ & 369 to $<507$ & $\geq 507$ & \\
\hline \multicolumn{6}{|l|}{ Mean (SD) } \\
\hline Total fruit and vegetables & $183.3(54.8)$ & 314.6 (31.2) & $430.3(39.3)$ & $688.8(196.9)$ & $<0.0001$ \\
\hline Energy (kJ day ${ }^{-1}$ ) & 8466 (2393) & 9095 (2486) & 9334 (2588) & $9925(2715)$ & $<0.0001$ \\
\hline SF-36 PCS score & $47.3(10.2)$ & $48.0(9.6)$ & $48.1(9.6)$ & $48.0(9.9)$ & 0.038 \\
\hline SF-36 MCS score & $52.3(9.6)$ & $53.1(8.9)$ & $53.2(8.6)$ & $53.4(8.9)$ & $<0.0001$ \\
\hline Age (years) & $60.4(9.2)$ & $61.8(9.3)$ & $62.3(9.0)$ & $63.0(9.0)$ & $<0.0001$ \\
\hline $\mathrm{BMI}\left(\mathrm{kg} \mathrm{m}^{-2}\right)$ & $26.2(3.2)$ & $26.3(3.2)$ & 26.4 (3.3) & 26.7 (3.2) & $<0.0001$ \\
\hline \multicolumn{6}{|l|}{ Number (\%) } \\
\hline Current smoker & $341(18.5)$ & $215(11.7)$ & $123(6.7)$ & $90(4.9)$ & $<0.0001$ \\
\hline Former smoker & 899 (48.8) & $992(53.8)$ & 1091 (59.1) & 1041 (56.5) & \\
\hline Non-smoker & 601 (32.6) & 638 (34.6) & 633 (34.3) & 710 (38.6) & \\
\hline Manual social class & $788(42.5)$ & $683(36.8)$ & 677 (36.5) & 632 (34.1) & $<0.0001$ \\
\hline $\begin{array}{l}\text { Lower than O-level or } \\
\text { no qualifications }\end{array}$ & $591(31.9)$ & $494(26.6)$ & $474(25.6)$ & $524(28.3)$ & $<0.0001$ \\
\hline Prevalent illness & $178(9.6)$ & $210(11.3)$ & $218(11.8)$ & $280(15.1)$ & $<0.0001$ \\
\hline Women $(n)$ & 2344 & 2344 & 2344 & 2344 & \\
\hline Quartile ranges $\left(\mathrm{g} \mathrm{day}^{-1}\right)$ & up to 331 & 331 to $<457$ & 457 to $<617$ & $\geq 617$ & \\
\hline \multicolumn{6}{|l|}{ Mean (SD) } \\
\hline Total fruit and vegetables & $242.1(64.9)$ & $394.6(36.3)$ & $530.2(45.1)$ & $833.2(238.9)$ & $<0.0001$ \\
\hline Energy $\left(\mathrm{kJ}\right.$ day $^{-1}$ ) & 7476 (2198) & 7946 (2068) & 8241 (2157) & $8862(2385)$ & $<0.0001$ \\
\hline SF-36 PCS score & $47.0(10.5)$ & $47.4(10.3)$ & $47.7(9.9)$ & $47.2(10.4)$ & 0.372 \\
\hline SF-36 MCS score & $50.6(10.2)$ & $51.5(9.6)$ & $52.5(8.8)$ & $52.4(9.6)$ & $<0.0001$ \\
\hline Age (years) & $59.3(9.3)$ & $60.5(9.2)$ & $61.0(9.0)$ & $61.6(9.1)$ & $<0.0001$ \\
\hline $\mathrm{BMI}\left(\mathrm{kg} \mathrm{m}^{-2}\right)$ & $25.8(4.2)$ & $25.9(4.3)$ & $26.1(4.1)$ & $26.4(4.4)$ & $<0.0001$ \\
\hline \multicolumn{6}{|l|}{ Number (\%) } \\
\hline Current smoker & $391(16.8)$ & $208(9.0)$ & $185(8.0)$ & $139(6.0)$ & $<0.0001$ \\
\hline Former smoker & $700(30.1)$ & $732(31.5)$ & 729 (31.4) & 775 (33.2) & \\
\hline Non-smoker & $1236(53.1)$ & $1383(59.5)$ & $1408(60.6)$ & $1418(60.8)$ & \\
\hline Manual social class & 911 (38.9) & $822(35.1)$ & 815 (34.8) & 780 (33.3) & 0.001 \\
\hline $\begin{array}{l}\text { Lower than O-level or } \\
\text { no qualifications }\end{array}$ & $1132(48.3)$ & $1013(43.2)$ & $972(41.5)$ & $973(41.5)$ & $<0.0001$ \\
\hline Prevalent illness & 225 (9.6) & 215 (9.2) & 219 (9.3) & $271(11.6)$ & 0.022 \\
\hline
\end{tabular}

EPIC - European prospective. Investigation into cancer; SD - standard deviation; SF-36 - 36-item short-form questionnaire; PCS Physical Component Summary; MCS - Mental Component Summary; BMI - body mass index; Manual social class - occupational social class III-manual, IV and V.

Table 2 Mean SF-36 PCS and MCS scores (and SE) in 7416 men and 9376 women aged 40-79 years in EPIC-Norfolk by quartiles of total fruit and vegetable consumption adjusted for age, BMI smoking, education, social class, prevalent illness and total energy intake

\begin{tabular}{|c|c|c|c|c|c|c|}
\hline & & \multicolumn{5}{|c|}{ Quartile category } \\
\hline & & 1 & 2 & 3 & 4 & $P$ \\
\hline \multicolumn{7}{|l|}{ SF-36 PCS } \\
\hline \multirow[t]{2}{*}{ Men } & Model A & $46.8(0.22)$ & $47.9(0.22)$ & $48.2(0.22)$ & $48.4(0.22)$ & $<0.0001$ \\
\hline & Model B & $46.8(0.22)$ & $47.9(0.21)$ & $48.1(0.21)$ & $48.5(0.22)$ & $<0.0001$ \\
\hline \multirow[t]{2}{*}{ Women } & Model A & $46.5(0.20)$ & $47.3(0.20)$ & $47.8(0.20)$ & $47.5(0.20)$ & $<0.0001$ \\
\hline & Model B & $46.6(0.20)$ & $47.2(0.20)$ & $47.8(0.20)$ & $47.7(0.20)$ & $<0.0001$ \\
\hline \multicolumn{7}{|l|}{ SF-36 MCS } \\
\hline Men & Model A & $52.5(0.21)$ & $53.1(0.21)$ & $53.1(0.21)$ & $53.2(0.21)$ & 0.063 \\
\hline Model B & $52.5(0.21)$ & $53.1(0.21)$ & $53.1(0.21)$ & $53.3(0.21)$ & & 0.068 \\
\hline Women & Model A & $50.9(0.20)$ & $51.5(0.20)$ & $52.4(0.20)$ & $52.2(0.20)$ & $<0.0001$ \\
\hline Model B & $50.9(0.20)$ & $51.4(0.20)$ & $52.4(0.20)$ & $52.3(0.20)$ & & $<0.0001$ \\
\hline
\end{tabular}

SF-36 - 36-item short-form questionnaire; PCS - Physical Component Summary; MCS - Mental Component Summary; SE - standard error; EPIC - European Prospective Investigation into Cancer; BMI - body mass index; Model A; - adjusted for age; Model B - adjusted for age, energy intake, BMI, smoking, education, social class and prevalent illness. 
measured by PCS and MCS scores of the SF-36 by multivariately adjusted models first controlling for age, BMI, smoking, education, social class and total energy intake, secondly after excluding current smokers, and thirdly after excluding those who reported prevalent illness at baseline.

Stratified analyses by social class and education level also showed that an increase in consumption of one portion of fruit and vegetables was positively associated with higher PCS and MCS scores in a linear fashion. Generally, the relationships were consistent (data not shown).

Table 4 shows multivariately adjusted odds ratios (ORs) and their corresponding 95\% confidence intervals (CIs) for likelihood of being in the arbitrarily defined good physical and mental health status (i.e. PCS or MCS score 255 ) using the lowest consumption category (quartile 1) as the reference category. In all three models (similar models to those in Table 3), the top quartile group compared with the bottom group was significantly associated with a higher likelihood of having a good physical functional health status in both men and women. Although the trends in this sample population suggest a similar relationship for mental functional health, relationships were less consistent between men and women. An increase in consumption of two portions of fruit and vegetable is associated with an $\sim 11 \%$ higher likelihood of having a good functional health status (OR $=1.11 ; 95 \%$ CI 1.04-1.18).

Using a different cut-off point at 60 (1 SD higher than the population mean) to identify people with a good physical and mental health status did not materially alter the results (data not shown).

\section{Discussion}

In this population-based study, we found a positive significant association between fruit and vegetable intake and self-reported physical functional health in men and women. The findings are less consistent for mental functional health.

In agreement with other studies and our previous report $^{28}$, higher fruit and vegetable consumption was associated with a higher level of education and nonmanual occupation in both men and women. Similar to findings from a recent study from Canada ${ }^{29}$, women reported higher intakes of fruit and vegetables compared with men. This could reflect gender differences in fruit and vegetable consumption or simply differences in reporting intake by men and women. A study that examined gender differences in fruit and vegetable intake showed that fewer men than women knew the current recommendations for fruit and vegetables intake, and fewer were aware of the links between fruit and vegetable consumption and disease prevention ${ }^{30}$. This, and other reasons, including food preferences, may influence the amount of fruit and vegetables consumed by men and women.

Positive trends were observed for the relationship between total fruit and vegetable consumption and mental functional health. However, this association was less consistent in men compared with women. Nevertheless, increases in one portion of fruit and vegetable consumption appeared to be related to higher PCS and MCS scores. The differential results between men and women may reflect the fact that total fruit and vegetable consumption is higher in women compared with men. It is also plausible that the composition or characteristics of men and women within the population studied may differ and, although we adjusted for possible confounders, we could not exclude the residual confounding or those unknown confounders, which were not adjusted for.

An obvious limitation in using FFQ data is measurement error $^{31,32}$. However, such random measurement error is likely to attenuate any associations found ${ }^{33,34}$.

Table 3 Multivariate regression models* for SF-36 PCS and MCS scores on fruit and vegetable intake (for an increase in consumption of one portion $(80 \mathrm{~g})$ of total fruit and vegetables per day) for men and women aged 40-79 years in EPIC-Norfolk

\begin{tabular}{|c|c|c|c|c|c|c|}
\hline & \multicolumn{3}{|c|}{ Men } & \multicolumn{3}{|c|}{ Women } \\
\hline & $n$ & $\beta$ (SE) & $P$ & $n$ & $\beta$ (SE) & $P$ \\
\hline \multicolumn{7}{|l|}{ SF-36 PCS } \\
\hline All & 7349 & $0.17(0.04)$ & $<0.0001$ & 9271 & $0.11(0.03)$ & 0.001 \\
\hline Excluding current smokers $†$ & 6605 & $0.16(0.04)$ & $<0.0001$ & 8381 & $0.12(0.03)$ & 0.001 \\
\hline \multirow{2}{*}{\multicolumn{7}{|c|}{ SF-36 MCS }} \\
\hline & & & & & & \\
\hline All & 7349 & $0.09(0.04)$ & 0.027 & 9271 & $0.17(0.03)$ & $<0.0001$ \\
\hline Excluding current smokers $†$ & 6605 & $0.07(0.04)$ & 0.10 & 8381 & $0.16(0.03)$ & $<0.0001$ \\
\hline Excluding prevalent illnessł & 6530 & $0.09(0.04)$ & 0.035 & 8446 & $0.18(0.03)$ & $<0.0001$ \\
\hline
\end{tabular}

SF-36 - 36-item short-form questionnaire; PCS - Physical Component Summary; MCS - Mental Component Summary; EPIC European Prospective Investigation into Cancer; $\beta$ - partial regression coefficient; SE - standard error.

*In all models, the variables were included simultaneously with every increase in consumption of one portion ( $80 \mathrm{~g}$ ) of total fruit and vegetables; variables used in the models were age, body mass index, smoking, education, social class, total energy intake, prevalent illness except the variable on which the model was stratified.

†Those who answered yes to the question 'Do you smoke cigarettes now?' in the baseline survey.

¥Prevalent illness were cancer, stroke, myocardial infarction and diabetes mellitus. 
Fruit and vegetable consumption and self-reported functional health in EPIC-Norfolk

Table 4 Multivariate adjusted odds ratio (95\% confidence interval) for the likelihood of having good physical or mental health status for quartiles of total fruit and vegetable consumption using the lowest quartile group as reference category

\begin{tabular}{|c|c|c|c|c|c|c|}
\hline & & \multicolumn{5}{|c|}{ Total fruit and vegetable consumption category } \\
\hline & & 1 & 2 & 3 & 4 & $P$ \\
\hline \multicolumn{7}{|c|}{ Good physical health status (PCS $\geq 55$ ) } \\
\hline \multirow[t]{2}{*}{ Model A } & Men & 1.00 & $1.03(0.88-1.21)$ & $1.08(0.92-1.27)$ & $1.30(1.11-1.53)$ & 0.007 \\
\hline & Women & 1.00 & $1.17(1.02-1.34)$ & $1.19(1.04-1.37)$ & $1.28(1.11-1.48)$ & 0.006 \\
\hline \multirow[t]{2}{*}{ Model B } & Men & 1.00 & $1.09(0.92-1.30)$ & $1.13(0.96-1.34)$ & $1.35(1.13-1.60)$ & 0.006 \\
\hline & Women & 1.00 & $1.20(1.04-1.40)$ & $1.22(1.05-1.42)$ & $1.35(1.16-1.57)$ & 0.001 \\
\hline \multirow{2}{*}{ Model C } & Men & 1.00 & $1.09(0.91-1.30)$ & $1.16(0.98-1.39)$ & $1.34(1.12-1.61)$ & 0.009 \\
\hline & Women & 1.00 & $1.24(1.06-1.45)$ & $1.26(1.08-1.48)$ & $1.38(1.18-1.62)$ & 0.001 \\
\hline \multicolumn{7}{|c|}{ Good mental health status (MCS $\geq 55$ ) } \\
\hline \multirow[t]{2}{*}{ Model A } & Men & 1.00 & $1.12(0.98-1.28)$ & $1.08(0.94-1.23)$ & $1.12(0.98-1.29)$ & 0.32 \\
\hline & Women & 1.00 & $1.08(0.96-1.21)$ & $1.23(1.09-1.38)$ & $1.32(1.17-1.49)$ & $<0.0001$ \\
\hline \multirow[t]{2}{*}{ Model B } & Men & 1.00 & $1.04(0.90-1.20)$ & $1.02(0.88-1.18)$ & $1.09(0.94-1.26)$ & 0.68 \\
\hline & Women & 1.00 & $1.06(0.94-1.20)$ & $1.25(1.10-1.41)$ & $1.35(1.19-1.54)$ & $<0.0001$ \\
\hline \multirow[t]{2}{*}{ Model C } & Men & 1.00 & $1.04(0.89-1.21)$ & $1.00(0.86-1.17)$ & $1.12(0.96-1.31)$ & 0.44 \\
\hline & Women & 1.00 & $1.01(0.89-1.16)$ & $1.24(1.09-1.42)$ & $1.36(1.19-1.56)$ & $<0.0001$ \\
\hline
\end{tabular}

PCS - Physical Component Summary score; MCS - Mental Component Summary score.

In all models, the variables were included simultaneously with quartiles of total fruit and vegetables categories. Model A - covariates included were age, body mass index, smoking, education, social class, total energy intake and prevalent illness; Model B - analyses repeated after exclusion of current smokers; Model C - analyses repeated after exclusion of participants who reported prevalent illnesses namely cancer, stroke, myocardial infarction and diabetes mellitus.

In his report, Perez used data from the first Canadian Community Health Survey and showed that the frequency of eating fruit and vegetables was positively related to not being overweight and not smoking ${ }^{29}$. In contrast to his finding, we found a positive association between BMI and total fruit and vegetable consumption in our cohort, but this association, though significant because of the large numbers, was of trivial magnitude $(0.5 \mathrm{~kg}$ between the top and bottom quartiles). We also found that smokers reported lower fruit and vegetable intake.

A recent randomised clinical trial (of behavioural counselling versus nutritional education counselling, $n=271$ ) targeted at people in a low-income neighbourhood showed improvements in physical functional health status with increased fruit and vegetable intake up to 12 months follow-up in both groups independently of age, gender, ethnicity, financial status, smoking, BMI and use of vitamin supplements ${ }^{35}$. Although a direct comparison could not be made with our study as it was conducted in a particularly high-risk population where the intervention would have most potential impact, our findings additionally suggest that higher consumption of fruit and vegetables is associated with better physical and mental functional health across the normal distribution of intake and functional health in a population.

People who are ill, or people who are in lower social class, and/or have a low education level, or people who smoke may eat less fruit and vegetables and this may confound the relationship between fruit and vegetable intake and functional health. Nevertheless, we adjusted for age, smoking, social class, education and prevalent illness, and repeated the analyses after excluding the current smokers and those who reported illness at baseline. Moreover, we observed that people with a prevalent illness may in fact report eating more fruit and vegetables suggesting health-related lifestyle behaviour might have changed in those who are diagnosed with a disease such as stroke, heart attack, diabetes or cancer.

Higher fruit and vegetable consumption could influence health through numerous biological mechanisms relating to myriad biologically active components ${ }^{36-38}$. These may be both short-term through influencing bowel habits, for example, or longer term through influencing risk of chronic diseases such as cardiovascular disease ${ }^{5}$ and mortality ${ }^{14}$. To examine the clinical relevance of differences in mean PCS and MCS scores, we arbitrarily defined good physical and mental health status using PCS and MCS scores $\geq 55$ ( 0.5 SD value over the population mean) and assessed the likelihood of being in good health by quartile categories of fruit and vegetable consumption. Consistent with results for the regression models using continuous variables, higher fruit and vegetable consumption was associated with a higher likelihood of reporting good functional health.

There are limitations in this study. Because we required participants who were willing to provide detailed information and participate in a long-term follow-up study, we only had a response rate of $40-45 \%$ for the baseline and follow-up survey. Nevertheless, the characteristics of this population are comparable with national samples, except for a slightly lower prevalence of smokers $^{18}$, and there was still a wide range of social class and educational status. Moreover, comparison between EPIC-HLEQ mean SF-36 scores and mean scores of age-sex standardised to UK population norms from the Health Survey for England, the Omnibus Survey in Great Britain and the Oxford Healthy Life Survey showed comparable results ${ }^{21}$. 
High intake of fruit and vegetables has been associated with lower risk of chronic diseases. We found a significant association between total consumption of fruit and vegetable and an individual's subjective health in a freeliving community. This may lend further support to public health advice to increase fruit and vegetable intake.

\section{Acknowledgements}

Ethics approval: Norwich Local Research Ethics Committee approved the study. The corresponding address for the LREC is Clinical Governance Department, Aldwych House, 57 Bethel Street, Norwich, UK.

Sources of funding: EPIC-Norfolk is supported by research programme grant funding from Cancer Research UK and the Medical Research Council, with additional support from the Stroke Association, British Heart Foundation, Department of Health, Europe Against Cancer Programme Commission of the European Union, Food Standards Agency, Research into Ageing, Academy of Medical Sciences and Wellcome Trust. The EPIC-Norfolk HLEQ research programme is supported by a programme grant from the Medical Research Council UK (G0300128).

Conflict of interest declaration: None.

Authorship responsibilities: K.T.K., S.A.B., N.E.D. and N.J.W. are principal investigators in the EPIC-Norfolk population study. P.G.S. is the principal investigator of the EPIC-Norfolk HLEQ programme. R.N.L. is responsible for data management, computing and data linkages. P.K.M. conducted the analysis. All co-authors contributed in writing of this paper. K.T.K. is the guarantor.

Acknowledgements: We would like to thank participants and general practitioners who took part in the study. We also thank the staff of EPIC-Norfolk and our funders.

\section{References}

1 Eikenberry N, Smith C. Healthful eating: perceptions, motivations, barriers, and promoters in low-income minnesota communities. Journal of the American Dietetic Association 2004; 104: 1158-61.

2 Djousse L, Arnett DK, Coon H, Province MA, Moore LL, Ellison RCO. Fruit and vegetable consumption and LDL cholesterol: the National Heart. Lung and Blood Institute Family Heart Study. American Journal of Clinical Nutrition 2004; 79: 213-7.

3 Rissanen TH, Voutilainen S, Virtanen JK, Venho B, Vanharanta M, Mursu J, et al. Low intake of fruits, berries and vegetables is associated with excess mortality in men: the Kuopio Ischaemic Heart Disease Risk Factor (KIHD) Study. Journal of Nutrition 2003; 133: 199-204.

4 John JH, Ziebland S, Yudkin P, Roe LS, Neil HA. Oxford Fruit and Vegetable Study Group. Effects of fruits and vegetable consumption on plasma antioxidant concentrations and blood pressure: a randomised controlled trial. Lancet 2002; 359: 1969-74.

5 Joshipura KJ, Hu FB, Manson JE, Stampfer MJ, Rimm EB, Speizer FE, et al. The effect of fruit and vegetable intake on risk for coronary heart disease. Annals of Internal Medicine 2001; 134: 1106-14.
6 Miura K, Greenland P, Stamler J, Liu K, Daviglus ML, Nakagawa $H$. Relation of vegetable, fruit, and meat intake to 7-year blood pressure changes in middle-aged men: the Chicago Western Electric Study. American Journal of Epidemiology 2004; 159: 572-80.

7 Cox BD, Whichelow MJ, Preyost AT. Seasonal consumption of salad vegetables and fresh fruit in relation to the development of cardiovascular disease and cancer. Public Health Nutrition 2000; 3: 19-29.

8 van't Veer P, Jansen MC, Klerk M, Kork FJ. Fruits and vegetables in the prevention of cancer and cardiovascular disease. Public Health Nutrition 2000; 3: 103-7.

9 Bingham SA, Day NE, Luben R, Ferrari P, Slimani N, Norat T, et al. Dietary fibre in food and protection against colorectal cancer in the European Prospective Investigation into Cancer and Nutrition (EPIC): an observational study. Lancet 2003; 361: 1496-501.

10 Pavia M, Pileggi C, Nobile CG, Angelillo IF. Association between fruit and vegetable consumption and oral cancer: a meta-analysis of observational studies. American Journal of Clinical Nutrition 2006; 83: 1126-34.

11 Michels KB, Giovannucci E, Chan E, Chan AT, Singhania R, Fuchs CS, et al. Fruit and vegetable consumption and colorectal adenomas in the Nurses' Health Study. Cancer Research 2006; 66: 3942-53.

12 Key TJ, Allen N, Appleby P, Overvad K, Tjonneland A, Miller A, et al. Fruits and vegetables and prostate cancer: no association among 1104 cases in a prospective study of 130544 men in the Eurpoean Prospective Investigation into Cancer and Nutrition. International Journal of Cancer 2004; 109: 119-24.

13 Hung HC, Merchant A, Willett W, Ascherio A, Rosner BA, Rimm E, et al. The association between fruit and vegetable consumption and peripheral arterial disease. Epidemiology 2003; 14: 659-65.

14 Khaw KT, Bingham S, Welch A, Luben R, Wareham N, Oakes $\mathrm{S}$, et al. Relation between plasma ascorbic acid and mortality in men and women in EPIC-Norfolk prospective study: a prospective population study. European Prospective Investigation into Cancer and Nutrition. Lancet 2001; 357: 657-63.

15 Steffen LM, Jacobs DR Jr, Stevens J, Shahar E, Carithers T, Folsom AR. Associations of whole-grain, refined-grain, and fruit and vegetable consumption with risks of all-cause mortality and incident coronary artery disease and ischemic stroke: the Atherosclerosis Risk in Communities (ARIC) Study. American Journal of Clinical Nutrition 2003; 78: 383-90.

16 Gundgaard J, Nielsen JN, Olsen J, Sorensen J. Increased intake of fruit and vegetables: estimation of impact in terms of life expectancy and healthcare costs. Public Health Nutrition 2003; 6: 25-30.

17 Tobias M, Turley M, Stefanogiannis N, Vander Hoorn S, Lawes C, Mhurchu CN, et al. Vegetable and fruit intake and mortality from chronic disease in New Zealand. Australian and New Zealand Journal of Public Health 2006; 30: 26-31.

18 Day N, Oakes S, Luben R, Khaw KT, Bingham S, Welch A. EPIC-Norfolk: study design and characteristics of the cohort. British Journal of Cancer 1999; 80(Suppl 1): 95-103.

19 Welch AA, Luben R, Khaw KT, Bingham SA. The CAFE computer program for nutritional analysis of the EPICNorfolk food frequency questionnaire and identification of extreme nutrient values. Journal of Human Nutrition and Dietetetics 2005; 18: 99-116.

20 Brazier JE, Harper R, Jones NMB, O'Caithain A, Thomas KJ, Usherwood T, et al. Validating the SF-36 health survey questionnaire - new outcome measure for primary care. British Medical Journal 1992; 305: 160-4.

21 Surtees PG, Wainwright NW, Khaw KT. Obesity, confidant support and functional health: cross-sectional evidence from 
the EPIC-Norfolk cohort. International Journal of Obesity and Related Metabolic Disorders 2004; 28: 748-58.

22 Ware JE, Snow KK, Kosinski M, Gandek B. SF-36 Health Survey: Manual and Interpretation Guide. Boston, MA: New England Medical Center, The Health Institute, 1993.

23 Ware JE, Kosinski M, Keller SD. SF-36 Physical and Mental Health Summary Scales: A User's Manual. Boston, MA: New England Medical Center, The Health Institute, 1994.

24 Lohman T, Roche A, Martorell R. Anthropometric Standardization Reference Manual. Champaign, IL: Human Kinetics Books, 1991.

25 Elias P, Halstead K, Prandy K. CASOC: Computer-Assisted Standard Occupational Coding. HMSO: London, 1993.

26 Taft C, Karlsson J, Sullivan M. Do SF-36 summary component scores accurately summarize subscale scores? Quality of Life Research 2001; 10: 395-404.

27 Ware JE, Kosinski M. Interpreting SF-36 summary health measures: a response. Quality of Life Research 2001; 10: 405-13, 415-20.

28 Shohaimi S, Welch A, Bingham S, Luben R, Day N, Wareham $\mathrm{N}$, et al. Residential area deprivation predicts fruit and vegetable consumption independently of individual educational level and occupational social class: a cross sectional population study in the Norfolk cohort of the European Prospective Investigation into Cancer (EPICNorfolk). Journal of Epidemiology and Community Health 2004; 58: 686-91.

29 Perez CE. Fruit and vegetable consumption. Health Reports 2002; 13: 23-31.

30 Baker AH, Wardle J. Sex differences in fruit and vegetable intake in older adults. Appetite 2003; 40: 269-75.

31 Day NE, McKeown N, Wong MY, Welch A, Bingham S. Epidemiological assesssment of diet: a comparison of a 7-day diary with a food frequency questionnaire using urinary markers of nitrogen, potassium and sodium. International Journal of Epidemiology 2001; 30: 309-17.

32 McKeown NM, Day NE, Welch AA, Runswick SA, Luben RN, Mulligan AA, et al. Use of biological markers to validate selfreported dietary intake in a random smaple of the European Prospective Investigation into Cancer United Kingdom Norfolk cohort. American Journal of Clinical Nutrition 2001; 74: 188-96.

33 Bingham SA, Luben R, Welch A, Wareham N, Khaw KT, Day N. Are imprecise methods obscuring a relation between fat and breast cancer? Lancet 2003; 362: 212-4.

34 Parr CL, Veierod MB, Laake P, Lund E, Hjartaker A. Test-retest reproducibility of a food frequency questionnaire (FFQ) and estimated effects on disease risk in the Norwegian Women and Cancer Study (NOWAC). Nutrition Journal 2006; 5: 4.

35 Steptoe A, Perkins-Porras L, Hilton S, Rink E, Cappuccio FP. Quality of life and self-rated health in relation to changes in fruit and vegetable intake and in plasma vitamins $\mathrm{C}$ and $\mathrm{E}$ in a randomised trial of behavioural and nutritional education counselling. British Journal of Nutrition 2004; 92: 177-84.

36 Howard MD, Gordon DT, Gatleb KA, Kerly MS. Dietary fructooligosaccharide and gum Arabic have variable effects on faecal and colonic microbiota and epithelial call proliferation in mice and rats. Journal of Nutrition 1995; 125: 2604-9.

37 Felippe CR, Calder PC, Vecchia MG, Campos MR, ManciniFilho J, Newsholme EA, et al. Fatty acid composition of lymphocytes and macrophages from rats fed fibre-rich diet: a comparison between oat bran and wheat bran enriched diets. Lipids 1997; 32: 587-91.

38 Chandalia M, Greg A, Lutjohann D, von Bergmann K, Grundy SM, Brinkley LJ. Beneficial effect of high dietary fibre intake in patients with type 2 diabetes mellitus. New England Journal of Medicine 2000; 342: 1392-8. 